\title{
Including negative externalities during transport infrastructure construction in assessment of investment projects
}

\author{
Serban Raicu, Dorinela Costescu *iD, Mihaela Popa and Mircea Augustin Rosca
}

\begin{abstract}
The paper presents a method for optimizing the financing option for transport infrastructure project. The execution time for large project is substantial and the social costs generated during the construction phase are insufficient included in the assessment models. These are the main reasons for starting the research to extend the project evaluation methods with procedures that consider also social costs during the implementation of the project, besides the social costs after work completion.

The proposed method aims to enhance the solution given by the current applied methods for investment assessment. Starting from the results of the present procedures of transport investment assessment, two approaches are presented. The first one assumes that the work starts at the reference year and different construction schemes can be applied. The optimal time of project implementation is determined considering the social costs during construction and after project implementation. In the second approach, the purpose is to determine the moments of the starting and the completion of the works for minimum of the losses caused by the social costs before and during the project implementation.

The paper emphasizes that social cost during transport infrastructure work must be considered in investment timing. In this regard, supplementary procedures can be added to the current method used for ranking of the transport infrastructure investments. For an investment measure identified as opportune, the proposed method aim to minimize the total social cost.
\end{abstract}

Keywords: Transport infrastructure planning, Investment timing, Social cost

\section{Introduction}

Transport investment projects that aim the development of new infrastructure or upgrading of the existing one need substantial investments. Included in the public investment category, the project financing requires technical, financial and economic substantiation $[1,2]$. Rational and reliable methods are necessary to compare the advantages and disadvantages of the projects and to establish the financing priorities. Therefore, assessment methods have been established at European or national level [1-9]. Various methods of transport investment assessment and planning have been compared in several studies [10-15]. Traditionally, transport investment decisions are based on conventional cost-benefit analysis

\footnotetext{
* Correspondence: dorinela.costescu@upb.ro

Polytechnic University of Bucharest, Splaiul Independentei 313, 060042 Bucharest, Romania
}

(CBA) converting the virtual impacts into monetary units, such as time savings, emissions, accidents [7, 1622]. Another category of methods consists of multi-criteria analysis (MCA), acknowledged as technique for assessment of sustainability at neighbourhood level [1, 23-28]. Strengths and weaknesses of the CBA and MCA and their applicability in decision-making processes for transport projects are emphasized by substantial studies [11, 24, 26, 27, 29-35]. The results of the accomplished studies are useful in identifying the appropriate method for transport project evaluation in a certain framework. Therefore, this paper focuses not on a comparative examination of the project assessment. The aim is to develop a model which could supplement any current applied method.

In intermediate assessments of investment projects for new infrastructure or upgrading of the existing one [36], 
significant social costs have been emphasized during construction. Usually, CBA studies consider externalities (such as safety, pollution etc.) before and after project implementation, but not during construction. Starting from this statement, a model to better reveal the implementation time in project evaluation is required.

Firstly, the implementation time for large project is substantial. If social costs generated during the construction phase are insufficient included in assessment, then the efficiency analysis may provide some inaccurate conclusions in terms of the necessity and suitability of certain projects. In most cases of upgrading and new capacity development projects for rail and road infrastructures, restriction measures are required during the implementation time (capacity reductions, traffic speed limitations, and safety measures). In addition to the cost generated by the restriction measures, there are social costs due to congestion, longer detour routes, traffic risks, consequences to the community of the riparian zones, etc. Figure 1 presents examples of projects with significant impact recorded during implementation. Generally, construction of a highway section or the upgrading of a road requires deviation of traffic on adjacent routes, generating supplementary costs for transport operators, users, and riparian zones. Alternative roads frequently have insufficient capacity or are in poor condition. Moreover, the negative effects of the traffic detour imply additional costs even after the project implementation (due to detour roads and environment degradation).

These types of consequences, assessed in monetary units, must be considered in the analysis of the economic efficiency of transport infrastructure projects. Socio-economic analyses that assess the efficiency of investments in transport infrastructure by reference to the immediate rate of return [20] must consider the additional social costs incurred during the investment. In this regard, in calculating of the immediate rate of return, additional social costs during the project execution should be added to investment value.

Secondly, the construction time for large infrastructure project can vary in relation with different ways of construction work accomplishment:

- With simultaneous work (several simultaneous or quasi-simultaneous construction sites on the whole infrastructure length) or

- With successive work (a single construction site that is moved along the infrastructure as the work is completed).

Obviously, these differences in the execution of the project are, both interdependently, reflected in the construction time and the investment amount. In this way, a major concern has been to determine how the current assessment method could be extended to include the amount of the invested capital and its relationship with the construction time and, on the other hand, the global social costs.

The presented model aims to identify the most appropriate time for beginning and the completion of work for transport infrastructure projects considering the social costs generated during three phases:

(i) the "no-project" reference phase,

(ii) during the implementation period, and.

(iii) after the completion of the work.

The paper is structured as follows. First, we present the methodology applied in the development of the proposed model. Then, the optimal time of project execution is determined considering the social costs during construction and after project implementation. Further, assuming that the obtained optimal time cannot be applied due to physical reasons, a procedure for selection of the most appropriate investment and construction scheme is developed. The presented procedure is exemplified for the case of one road section upgrading. Finally, we look at solution for scheduling of work considering social costs before, during and after project implementation.

\section{Methodology}

The decision-making and planning process for large transport infrastructures needs trustworthy method to compare the advantages and disadvantages of the project, and to hierarchize the socio-economic attributes of the project variants. Generally, the frame of the assessment and planning of the investment projects is established at European and national level, even many disparities appear due to legal and administrative procedures $[3,9,19,28]$. Starting from the main frame of the project assessment, this research aims to add a model for further analysis of the investment timing, to minimize the global social cost.

This paper introduces an assessment method that considers the social costs incurred during the investment work on the transport infrastructure. These impacts have frequently been ignored in the economic analyses of the investment efficiency. The analyses consider the estimated impacts, both during the work and after the completion of the project, by comparison with "no project" status. Without the social costs that are generated during the construction phase, the efficiency analysis may provide some distorted conclusions in terms of the necessity and suitability of certain projects. The social costs supported by users, riparian zones and communities are significant, because the major transport infrastructures typically 


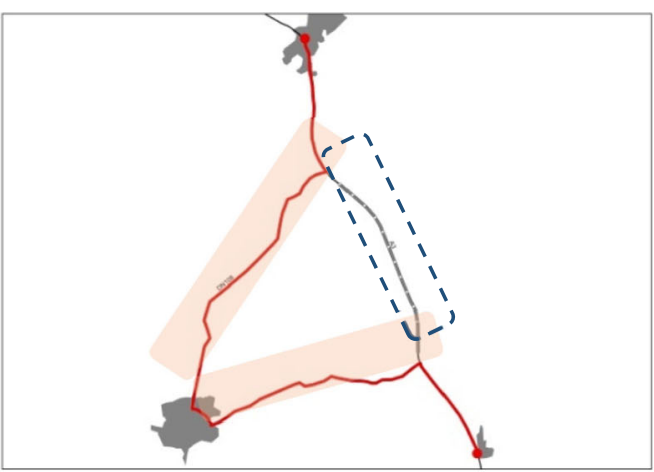

a

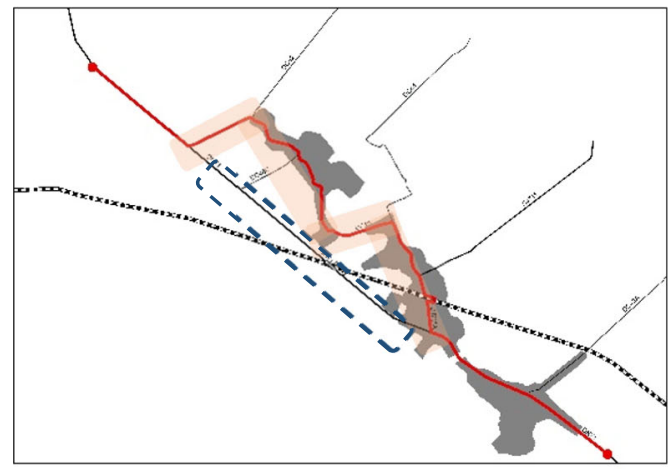

b

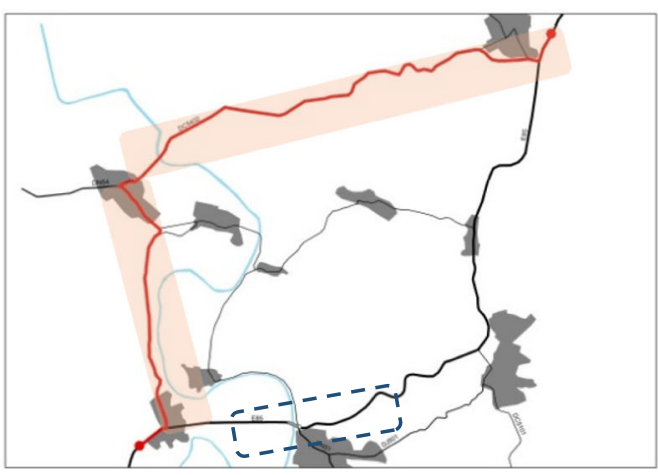

c

\section{Legend}

1 . Construction area

Area of unevaluated impact during work

- Route used during project implementation

City area

\section{Legend}

1 Construction area

Area of unevaluated impact during work

- Route used during project implementation

... Railroad

City area

Legend

1- ? Construction area

Area of unevaluated impact during work

- Route used during project implementation

City area

Fig. 1 Example of supplementary impact necessary to be evaluated for project in traffic infrastructure. a New road section project: traffic detour on $16 \mathrm{~km}$ adjacent national roads and through next city for 2 years of work; additional social costs including 11.4 mills. Euro time value and 1.15 mills. Euro emission costs. b National road upgrading project: impact during work for the road bypass on railway - heavy traffic detour on $2.5 \mathrm{~km}$ regional and county roads for 2 years; not comprised additional social costs including 4.6 mills. Euro time value and 0.15 mills. Euro emission costs. c National road modernization project: impact during work for a road junction upgrading - heavy traffic detoured on $15 \mathrm{~km}$ regional roads for 2 years; not comprised additional social costs including 15.6 mil. Euro time value and 1.18 mills. Euro emission costs

require a long period of time for construction, both upgrading an existing infrastructure and construction a new infrastructure.

The proposed method uses as input data the results of the present procedures of transport investment assessment (Fig. 2). The next assumptions are considered:
- The project can be completed in a minimum time (e.g. with many simultaneous construction sites, works at night), requiring a maximum investment amount, but reducing the social cost during the work, and producing earlier social benefits;

- The project can be completed in a maximum time with a minimum investment mount, a certain social 


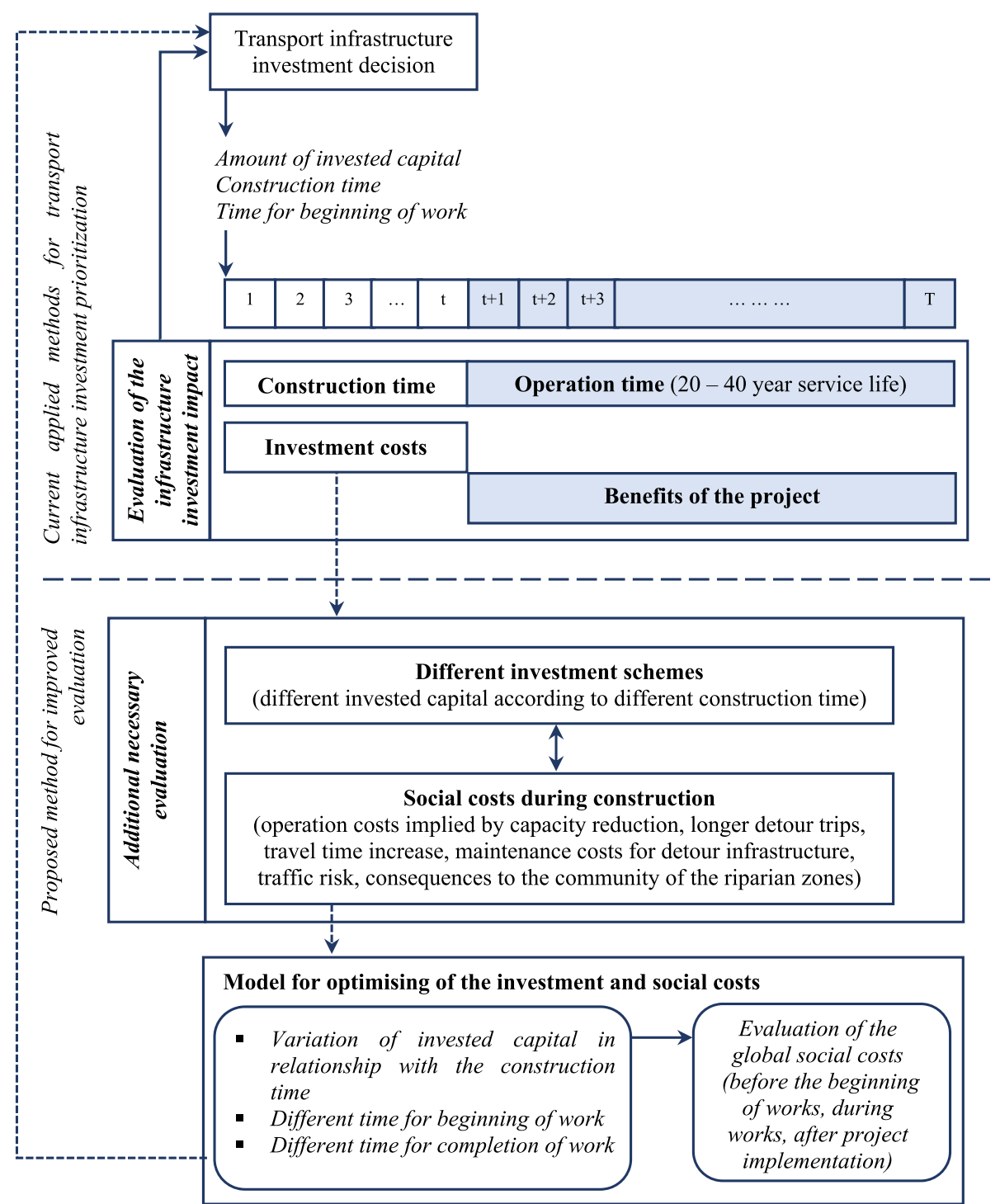

Fig. 2 Flowchart of procedures for transport infrastructure investment evaluation

cost during the works and the later achievement of the social benefits;

- For time of the project execution between the minimum time (corresponding to the maximum investment amount) and the maximum time, the investment value varies linearly between the maximum and minimum values. Not always minimum construction time corresponds to higher investment costs. But in this research, the statement of a descending relationship between the investment amount and the implementation time refers to cases when the traffic closing, and the use of the alternative routes are necessary (Fig. 1).

Two approaches are developed. The first one assumes that the work starts only at the reference year and aims to determine the optimal time of project implementation for maximum difference between (Fig. 3):

- The economy achieved by reducing the investment amount corresponding to an implementation time higher than the minimum time

- Additional social costs caused by prolonging the project implementation time.

The goal in the second approach is to determine the time of the beginning of the work and the time of the completion for minimum sum of:

- Losses caused by social costs before and during the project implementation; 


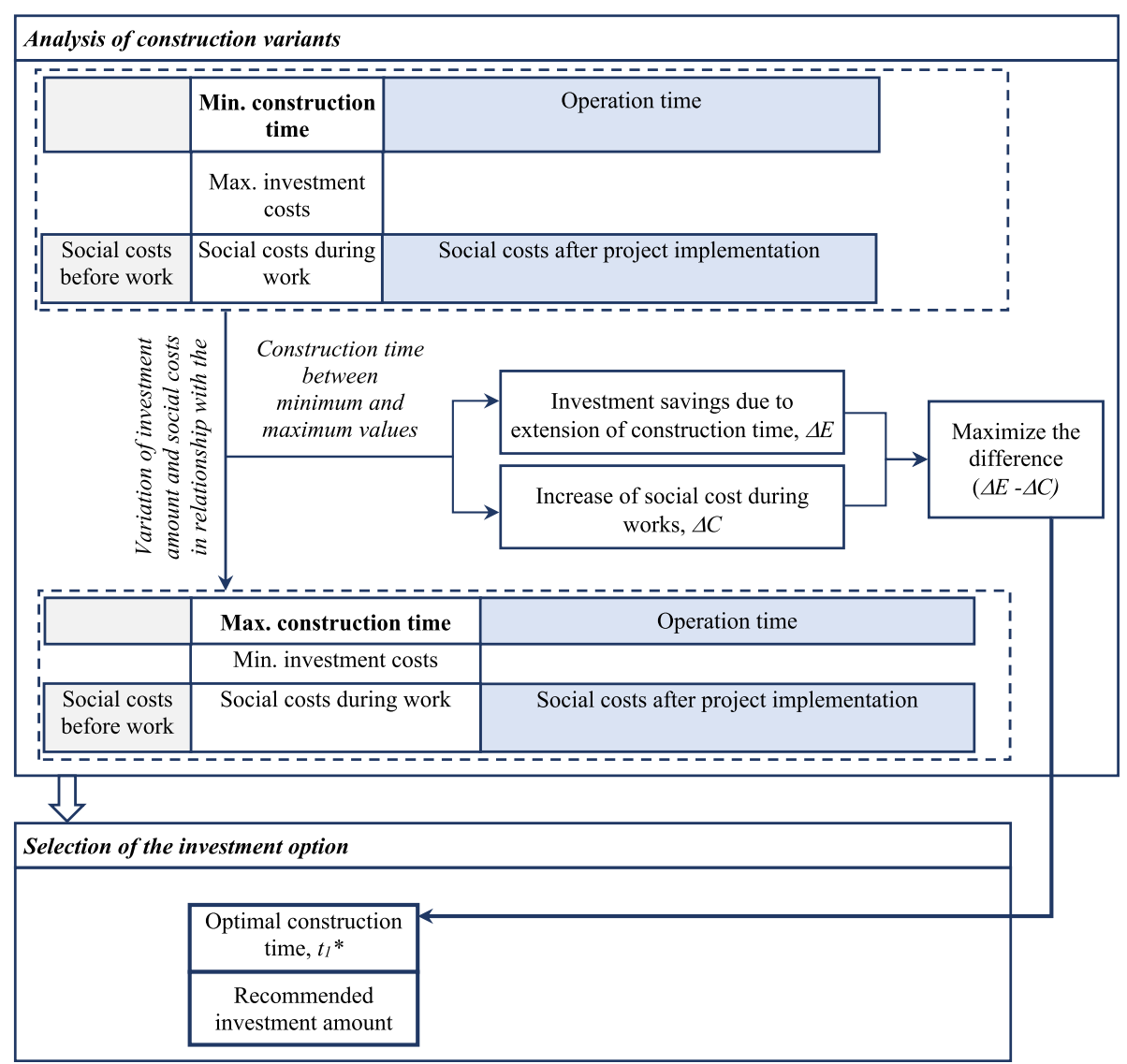

Fig. 3 The structure of the model for selection of the most appropriate investment option

- The necessary investment amount corresponding to the time of the project implementation.

\section{Time for work implementation vs. socio- economic costs}

Let us to consider a certain section of the transport infrastructure planned for upgrading (or new construction) work, and then, let us to consider the following cases:

- The entire infrastructure section is opened for work; minimum completion time, $\theta_{m}$, is obtained with the maximum annual amount of investment capital, $I_{M}$ (there are higher costs for more equipment, the management of a larger field of work, etc.)

- The infrastructure section is approached "step-bystep", considering the separation of several subsections; the project is implemented for maximum time, $\theta_{M}$, and minimum annual amount of investment capital, $I_{m}$.

These hypotheses are easily accepted, especially when the construction company is unique. Between these two extreme situations, we consider the year $t_{1}$, for the completion time and the related amount of investment, $I_{t 1}$ (Fig. 4).

In case of a linear function of the investment amount with respect to the completion time, $t_{1}$, we have the following:

$$
I_{t 1}=I_{m}+\frac{I_{M}-I_{m}}{\theta_{M}-\theta_{m}}\left(\theta_{M}-t_{1}\right), \theta_{m}<\mathrm{t}_{1} \leq \theta_{M}
$$

It is well-known that there are many uncertainties in estimating the total amount of capital investment for large transport infrastructures [37, 38]. However, in our approach, we acknowledge that the total discounted investment amounts respect the following relations:

$$
\sum_{t=1}^{\theta_{m}} \frac{I_{M}}{(1+\Delta)^{t}}>\sum_{t=1}^{t_{1}} \frac{I_{t 1}}{(1+\Delta)^{t}}>\sum_{t=1}^{\theta_{M}} \frac{I_{m}}{(1+\Delta)^{t}}
$$

where $\Delta$ represents a given discounted rate.

For the annual variation $i$ of the investment amount between $I_{m}$ and $I_{M}$ : 


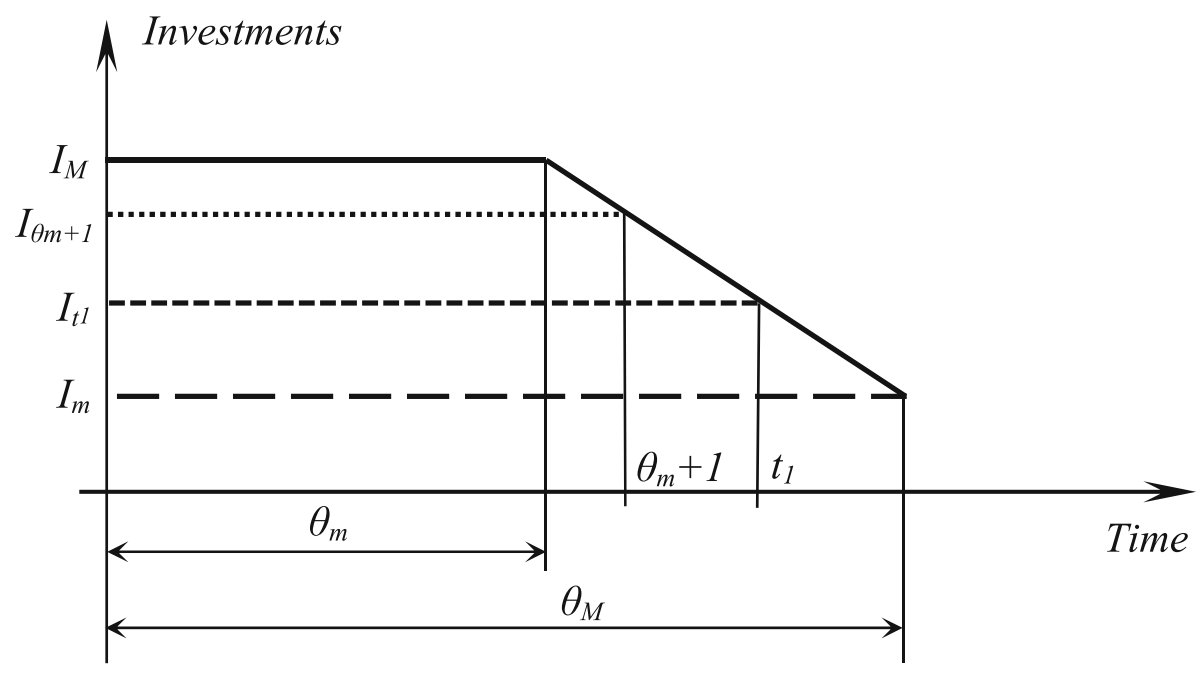

Fig. 4 The amount of annual investment as a rectilinear function of the completion time

$$
i=\frac{I_{M}-I_{m}}{\theta_{M}-\theta_{m}}
$$

Eq. (2) is satisfied for $t=\theta_{m}+1$ if the following condition is also satisfied (Fig. 4):

$$
I_{M} \sum_{t=1}^{\theta_{m}} \frac{1}{a^{t}}>\left(I_{M}-i\right) \sum_{t=1}^{\theta_{m}+1} \frac{1}{a^{t}}
$$

where $a=1+\Delta$.

Thus, the result is:

$$
i\left(\sum_{t=1}^{\theta_{m}} \frac{1}{a^{t}}+\frac{1}{a^{\theta_{m}+1}}\right)>I_{M} \frac{1}{a^{\theta_{m}+1}}
$$

which, after successive calculations, leads to the following:

$$
i>I_{M} \frac{a-1}{a^{\theta_{m}+1}-1} .
$$

If eq. (6) is not satisfied, then prolonging the completion time by only 1 year does not necessarily lead to a certain level of savings in invested capital (by comparison with the completion time, $\left.\theta_{m}\right)$. However, when eq. (6) is not satisfied, there remains the possibility of obtaining some savings in invested capital if the completion time is prolonged by more than 1 year.

We consider steady and linear traffic increases for all periods, before the beginning of the work, during the project implementation, and after the project completion. Consequently, the related socio-economic costs for those different periods have the same linear increasing shape (Fig. 5) and are denoted by $\mathrm{C}_{a}$ for the "no-project" status, $\mathrm{C}_{i}$ for the period during the work implementation, and $\mathrm{C}_{p}$ for the period after completion and opening for operation. The terms $C_{a}^{0}, C_{i}^{0}$, and $C_{p}^{0}$ are costs at the reference year; $c_{a}=\operatorname{tg} \alpha_{a}, \quad c_{i}=\operatorname{tg} \alpha_{i}$ and $c_{p}=\operatorname{tg} \alpha_{p}$ are the slopes of the linear cost functions (according to the notation in Fig. 5).

For the first examination, we assume that the work starts only at the beginning of the reference year (at $t_{0}=$ $0)$. We define the following terms:

- $\Delta C$ - the additional socio-economic costs during the extension of the work completion beyond the same minimum completion time, $\theta_{m}$ (Fig. 6.a).

- $\Delta E$ - the investment savings when the completion time is extended to $t_{1}$ (Fig. 6.b), beyond the minimum completion time, $\theta_{m}$ (which is accomplished when the maximum investment amount, $I_{M}$, is spent).

The objective is to determine the optimal time for the completion of work, $t_{1}{ }^{*}$, when the difference, $\delta$, between the investment savings and the additional social cost is the maximum, which means:

$$
\max \delta=\Delta E-\Delta C
$$

According to Fig. 6 (based on the shaded areas $A_{\oplus}$ and $\left.A_{\ominus}\right)$, we have the following:

$$
\Delta E=\sum_{t=1}^{\theta_{m}} I_{M} \frac{1}{a^{t}}-\sum_{t=1}^{t_{1}} I_{t 1} \frac{1}{a^{t}}
$$

The total additional socio-economic costs, discounted at $t_{1}$, are as follows:

$$
\Delta C=\sum_{t=\theta_{m}+1}^{t_{1}}\left(\left(C_{i p}^{0}+c_{i p} \cdot t\right) \frac{1}{a^{t}}\right)
$$

where $C_{i p}^{0}=C_{i}^{0}-C_{p}^{0}$ and $c_{i p}=c_{i}-c_{p}$. 


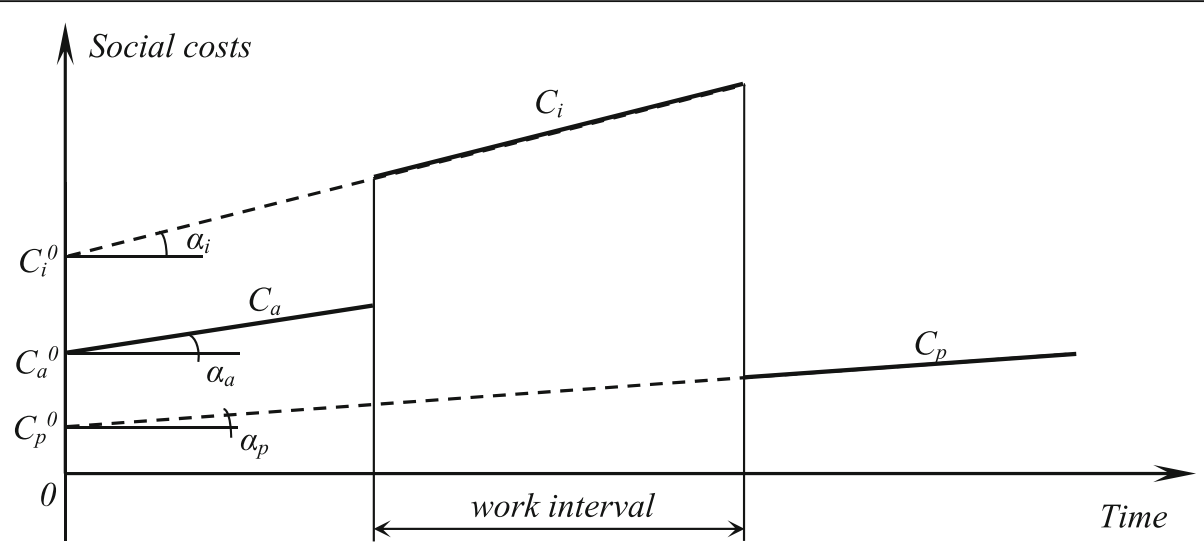

Fig. 5 Social costs: before the beginning of the work $\left(C_{a}\right)$, during the work $\left(C_{i}\right)$ and after the completion of the work $\left(C_{p}\right)$
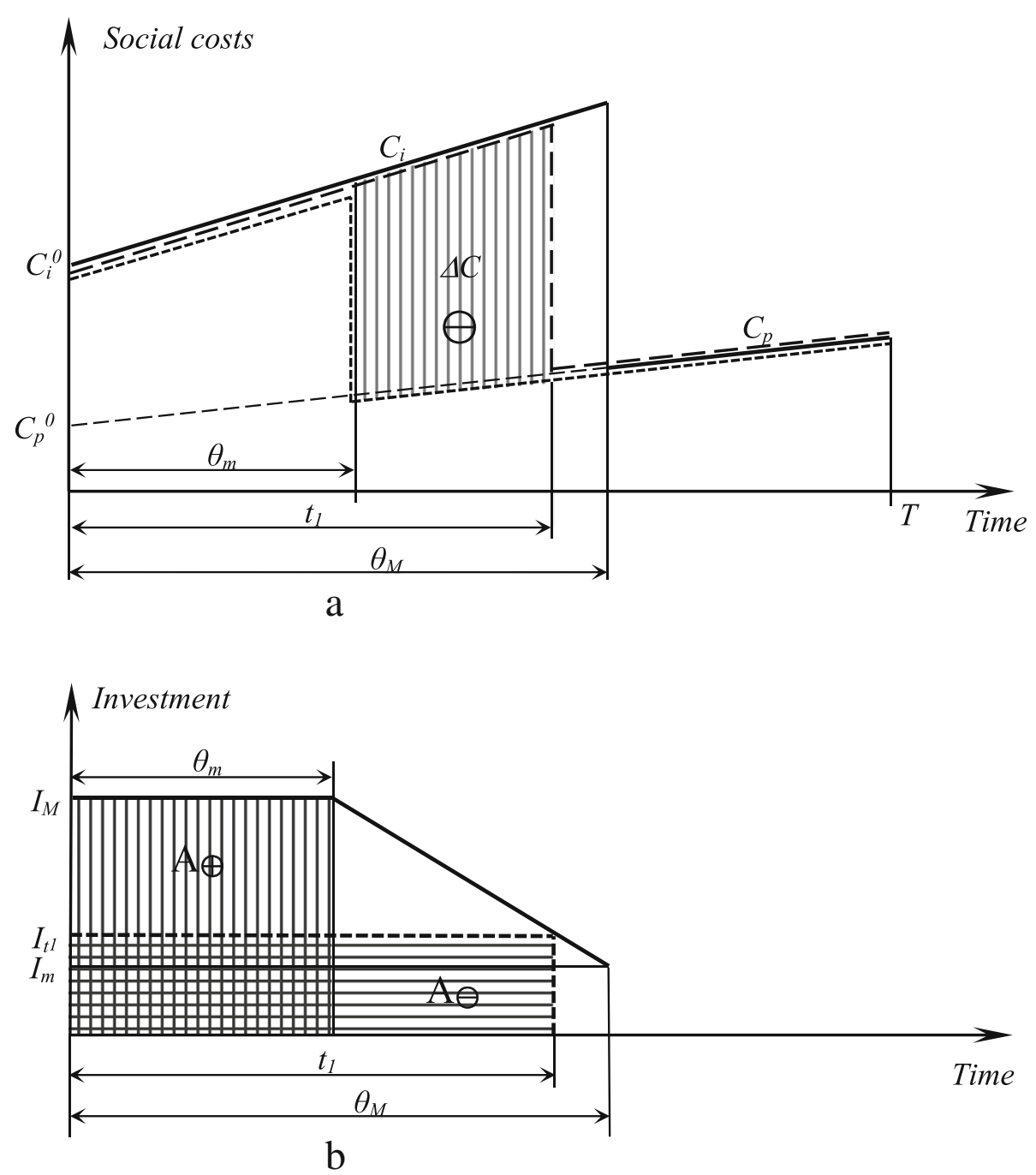

Fig. 6 Additional social costs and investment savings due to the extension of work duration until. a) increasing the additional social cost during the work, $\Delta C \mathbf{b})$ investment savings due to the extension of work duration, $\Delta \mathrm{E}=\mathrm{A} \oplus-\mathrm{A} \ominus t_{1}\left(\theta_{m} \leq t_{1}<\theta_{M}\right)$ 
After the substitution of $\Delta E$ and $\Delta C$ in Eq. (3) and after simultaneously adding and subtracting $\sum_{t=1}^{\theta_{m}}\left(\left(C_{i p}^{0}\right.\right.$ $\left.+c_{i p} \cdot t\right) \frac{1}{a^{t}}$ ), we obtain the following:

$$
\begin{aligned}
\delta= & \sum_{t=1}^{\theta_{m}} I_{M} \frac{1}{a^{t}}-\sum_{t=1}^{t_{1}} I_{t 1} \frac{1}{a^{t}}-\sum_{t=1}^{t_{1}}\left(\left(C_{i p}^{0}+c_{i p} \cdot t\right) \frac{1}{a^{t}}\right) \\
& +\sum_{t=1}^{\theta_{m}}\left(\left(C_{i p}^{0}+c_{i p} \cdot t\right) \frac{1}{a^{t}}\right) .
\end{aligned}
$$

Because the sum $\sum_{t=1}^{\theta_{m}} I_{M} \frac{1}{a^{t}}+\sum_{t=1}^{\theta_{m}}\left(\left(C_{i p}^{0}+c_{i p} \cdot t\right) \frac{1}{a^{t}}\right)$ has a constant value (noted here by $K$ ), Eq. (7) becomes the following:

$$
\delta=K-\left(\sum_{t=1}^{t_{1}} I_{t 1} \frac{1}{a^{t}}+\sum_{t=1}^{t_{1}}\left(\left(C_{i p}^{0}+c_{i p} \cdot t\right) \frac{1}{a^{t}}\right)\right),
$$

which means that the following expression needs to reach its minimum:

$$
\begin{aligned}
\delta_{1}= & \sum_{t=1}^{t_{1}} I_{t 1} \frac{1}{a^{t}} \\
& +\sum_{t=1}^{t_{1}}\left(\left(C_{i p}^{0}+c_{i p} \cdot t\right) \frac{1}{a^{t}}\right) \rightarrow \min .
\end{aligned}
$$

The optimum completion time, $t_{1}{ }^{*}$, represents the time $t_{1}$ for which $\delta_{1}$ is the minimum (when the work starts in the reference year).

Because $I_{t 1}=I_{m}+i\left(\theta_{M}-t_{1}\right)$ and $I_{t 1}=I_{M}-i\left(t_{1}-\theta_{m}\right)$, the result is:

$$
\delta_{1}=\sum_{t=1}^{t_{1}}\left(I_{m}+i\left(\theta_{M}-t_{1}\right)\right) \frac{1}{a^{t}}+\sum_{t=1}^{t_{1}}\left(\left(C_{i p}^{0}+c_{i p} \cdot t\right) \frac{1}{a^{t}}\right),
$$

or

$$
\delta_{1}=\sum_{t=1}^{t_{1}}\left(\left(I_{m}+C_{i p}^{0}+i\left(\theta_{M}-t_{1}\right)\right) \frac{1}{a^{t}}\right)+c_{i p} \sum_{t=1}^{t_{1}}\left(\frac{t}{a^{t}}\right) .
$$

After successive calculations of the sums in Eq. (14), we obtain the following:

$$
\begin{aligned}
\delta_{1}= & \left(I_{m}+C_{i p}^{0}+i\left(\theta_{M}-t_{1}\right)\right)\left(\frac{1}{a-1}\right)\left(1-\frac{1}{a^{t_{1}}}\right) \\
& +c_{i p}\left(\frac{1}{a-1}\right)\left(\frac{a}{a-1}\left(1-\frac{1}{a^{t_{1}}}\right)-\frac{t_{1}}{a^{t_{1}}}\right) .
\end{aligned}
$$

The derivative of Eq. (15) with respect to $t_{1}$ is as follows: $i a^{t_{1}}-i+c_{i p}-\left(I_{M}+C_{i p}^{0}+i \theta_{m}+c_{i p}\left(\frac{a}{a-1}\right)\right) \ln a-\left(i-c_{i p}\right) t_{1} \ln a=0$.

Then, we denote by

$$
\left\{\begin{array}{l}
\gamma_{1}=\left(c_{i p}-i\right) \ln a \\
\gamma_{2}=\left(i-c_{i p}\right)+\left(I_{M}+i \theta_{m}+C_{i p}^{0}+c_{i p}\left(\frac{a}{a-1}\right)\right) \ln a,
\end{array}\right.
$$

which means that we must determine the solution for the following equation:

$$
i a^{t_{1}}=\gamma_{1} t_{1}+\gamma_{2} \text {. }
$$

The accepted solution for Eq. (18) is the solution that respects the following restrictions: $\gamma_{1}<0$ and $\gamma_{2}>i$. The solutions to Eq. (18), for different values of $\gamma_{1}$ and $\gamma_{2}$, must respect the following constraint:

$$
\theta_{m}<\mathrm{t}_{1}{ }^{*} \leq \theta_{M} .
$$

The interval of the desired values of $t_{1}{ }^{\prime \prime}$ is obtained through the following condition: the investment savings amount, $\Delta \mathrm{E}$, due to prolonging the completion time beyond the minimum time, $\theta_{m}$, must surpass the additional social cost, $\Delta \mathrm{C}$, generated by the same reason, i.e., prolonging the completion time.

Considering the additional social costs incurred during the construction of the infrastructure projects, the extension of the project implementation over the technical and financial minimum time can be accepted only if it is offset by reduction in investment costs. Otherwise, Eq. (18) has no solutions.

\section{Selection of the investment option}

Let us to consider the following alternative hypotheses: after the optimisation calculus, there is now obtained a work completion time, $\mathrm{t}_{1}$, but the decision-maker has no ability to define a practical plan for work to achieve it and, consequently, to achieve the related amount of investment, $\mathrm{I}_{\mathrm{t}_{1}}$.

In such cases, there must be a clear selection of one of two options:

(i) completion of the work with the maximum investment amount in the fastest time $\theta_{m}$ or, by contrast,

(ii) working slowly until the completion time $\theta_{M}$ but using the minimum investment amount.

Occasionally, there are additional exogenous restrictions that impose a certain investment option/strategy without any other type of analysis (for example, when severe weather conditions impose the performance of work during certain periods of the year).

Regardless, the selection between the two options is based on the comparison between the total costs (socioeconomic cost and the investment amount) during the work implementation and the savings of the social costs 
(computed as a difference between the "no-project" status and the "completed project" situation).

For both options (Fig. 7), we have the maximum savings of the social costs, $E_{M}$, in the case of maximum investment, $I_{M}$ :

$$
\begin{aligned}
E_{M}= & -\sum_{t=1}^{\theta_{m}}\left(\left(C_{i a}^{0}+c_{i a} \cdot t\right) \frac{1}{a^{t}}\right)-\sum_{t=1}^{\theta_{m}}\left(\mathrm{I}_{M} \frac{1}{a^{t}}\right) \\
& +\sum_{t=\theta_{m}+1}^{T}\left(\left(C_{a p}^{0}+c_{a p} \cdot t\right) \frac{1}{a^{t}}\right),
\end{aligned}
$$

and the minimum savings, $E_{m}$, in the case of the minimum investment, $I_{m}$ :

$$
\begin{aligned}
E_{m}= & -\sum_{t=1}^{\theta_{M}}\left(\left(C_{i a}^{0}+c_{i a} \cdot t\right) \frac{1}{a^{t}}\right)-\sum_{t=1}^{\theta_{M}}\left(\mathrm{I}_{m} \frac{1}{a^{t}}\right) \\
& +\sum_{t=\theta_{M}+1}^{T}\left(\left(C_{a p}^{0}+c_{a p} \cdot t\right) \frac{1}{a^{t}}\right),
\end{aligned}
$$

where

$$
C_{i a}^{0}=C_{i}^{0}-C_{a}^{0}, c_{i a}=c_{i}-c_{a} \text { and } C_{a p}^{0}=C_{a}^{0}-C_{a p}^{0}, c_{a p}=c_{a}-c_{p} .
$$

The first negative term in Eq. (20) and in Eq. (21) represents the increasing total social costs during the work implementation (by comparison with the "no-project" status); the second term is the total discounted investment amount; and the last term is the total amount of benefits after the completion of the work until the planning horizon, $\mathrm{T}$.

We obtain the following:

$$
\begin{aligned}
E_{m}-E_{M}= & -\sum_{t=\theta_{m}+1}^{\theta_{M}}\left(\left(C_{i p}^{0}+c_{i p} \cdot t\right) \frac{1}{a^{t}}\right)-\sum_{t=1}^{\theta_{M}}\left(\mathrm{I}_{m} \frac{1}{a^{t}}\right) \\
& +\sum_{t=1}^{\theta_{m}}\left(I_{M} \frac{1}{a^{t}}\right),
\end{aligned}
$$

which means that the option for the savings investment, $E_{m}-E_{M}>0$, is recommended only if:

$$
\begin{aligned}
& \sum_{t=1}^{\theta_{m}}\left(I_{M} \frac{1}{a^{t}}\right)-\sum_{t=1}^{\theta_{M}}\left(\mathrm{I}_{m} \frac{1}{a^{t}}\right) \\
& >\sum_{t=\theta_{m}+1}^{\theta_{M}}\left(\left(C_{i p}^{0}+c_{i p} \cdot t\right) \frac{1}{a^{t}}\right),
\end{aligned}
$$

or, in other words, when the discounted savings of
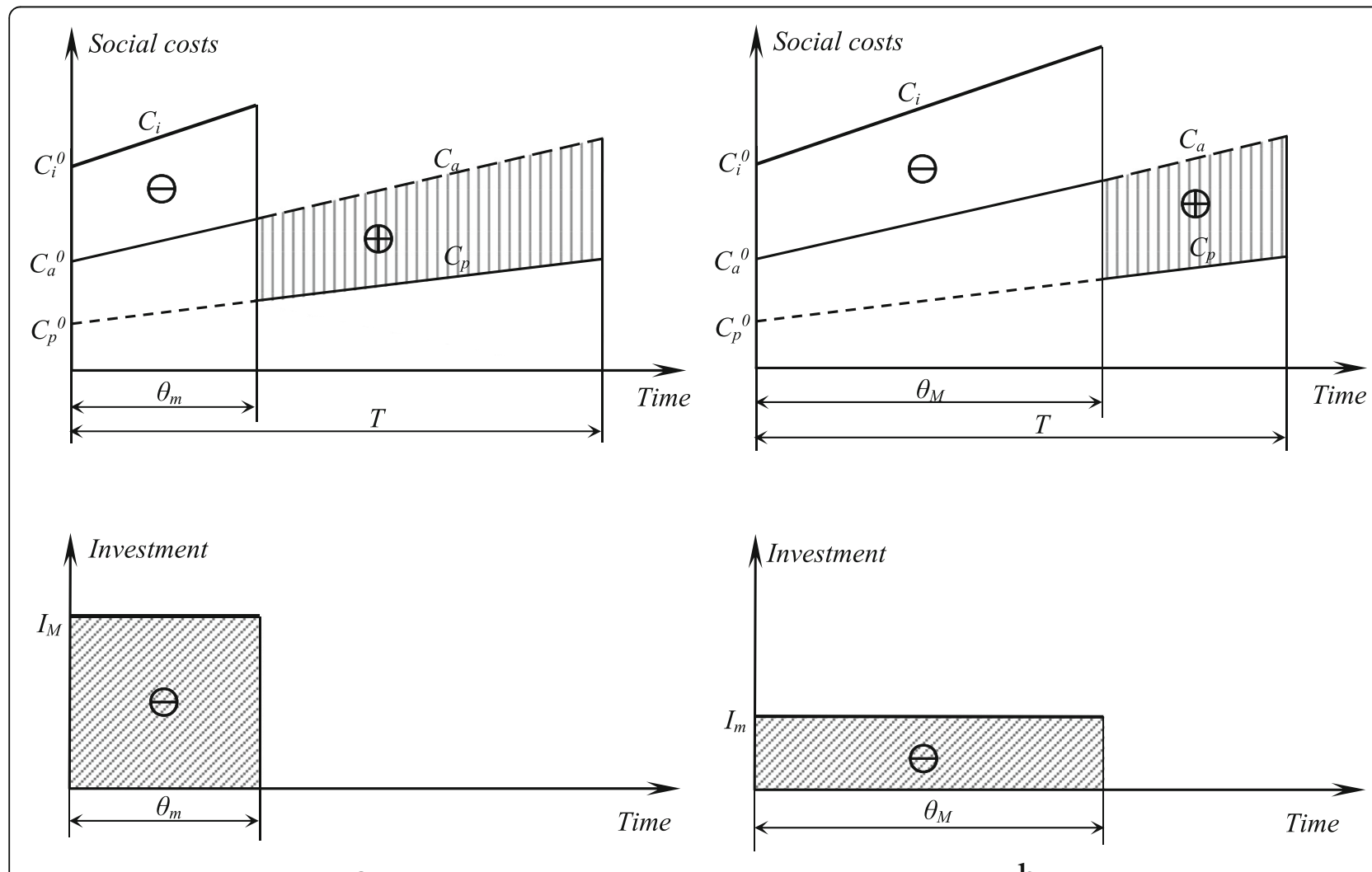

a

b

Fig. 7 Investment amount, additional social costs and savings of the social costs after the completion of the work for both options. a Minimum time for work. $\mathbf{b}$ Maximum time for work 
investment are larger than the additional social costs due to prolonging the completion time from $\theta_{m}$, to $\theta_{M}$.

\section{The time estimation of the beginning and completion of work}

In this section, we suppose that there is no capacity restriction (or that there is plenty of capacity) or that the project is exclusively related to the decrease in the social cost (which means increasing the quality of the traffic flow). Under these conditions, the purpose is to determine the moments of the starting and the completion of the works for minimum of the losses caused by the social costs before and during the project implementation (Fig. 8). The time of the beginning and the time of the completion of the work are the key elements for all three phases of the total social costs, i.e., before the beginning of the project, during the work, and after the completion, for the entire planning horizon.

Thus, the time of the beginning of the work $\left(t_{0}\right)$ and the completion time $\left(t_{1}\right)$ result from the discounted total loss (denoted by $L$ ), coming from the amount of the additional social costs (before and during the work), compared to the total discounted cost after the completion of the project (according to the shaded areas in Fig. 9.a), plus the total discounted investment, $I_{t 1}$, in the $\left(t_{1}-t_{0}\right)$ interval (shaded area in Fig. 9.b).

We have the following:

$$
\begin{aligned}
L & =\sum_{t=1}^{t_{1}}\left(\left(C_{a}^{0}+c_{a} \cdot t\right) \frac{1}{a^{t}}\right)+\sum_{t=t_{0}+1}^{t_{1}}\left(\left(C_{i}^{0}+c_{i} \cdot t\right) \frac{1}{a^{t}}\right) \\
& -\sum_{t=1}^{t_{1}}\left(\left(C_{p}^{0}+c_{p} \cdot t\right) \frac{1}{a^{t}}\right)-\sum_{t=t_{0}+1}^{t_{1}}\left(\left(C_{a}^{0}+c_{a} \cdot t\right) \frac{1}{a^{t}}\right) \\
& +\sum_{t=t_{0+1}}^{t_{1}}\left(I_{t 1} \cdot \frac{1}{a^{t}}\right) \rightarrow \min
\end{aligned}
$$

According to Eqs. (1)-(3) and Eqs. (21)-(22), respectively, we obtain:

$$
\begin{aligned}
L= & C_{a p}^{0} \sum_{t=1}^{t_{1}}\left(\frac{1}{a^{t}}\right)+c_{a p} \sum_{t=1}^{t_{1}}\left(\frac{t}{a^{t}}\right) \\
& +c_{i a} \sum_{t=t_{0}+1}^{t_{1}}\left(\frac{t}{a^{t}}\right) \\
& +\left(C_{i a}^{0}+I_{m}+i\left(\theta_{M}+t_{0}-t_{1}\right)\right) \sum_{t=t_{0}+1}^{t_{1}}\left(\frac{1}{a^{t}}\right) .
\end{aligned}
$$

Solving the sums in Eq. (26), we obtain the following:

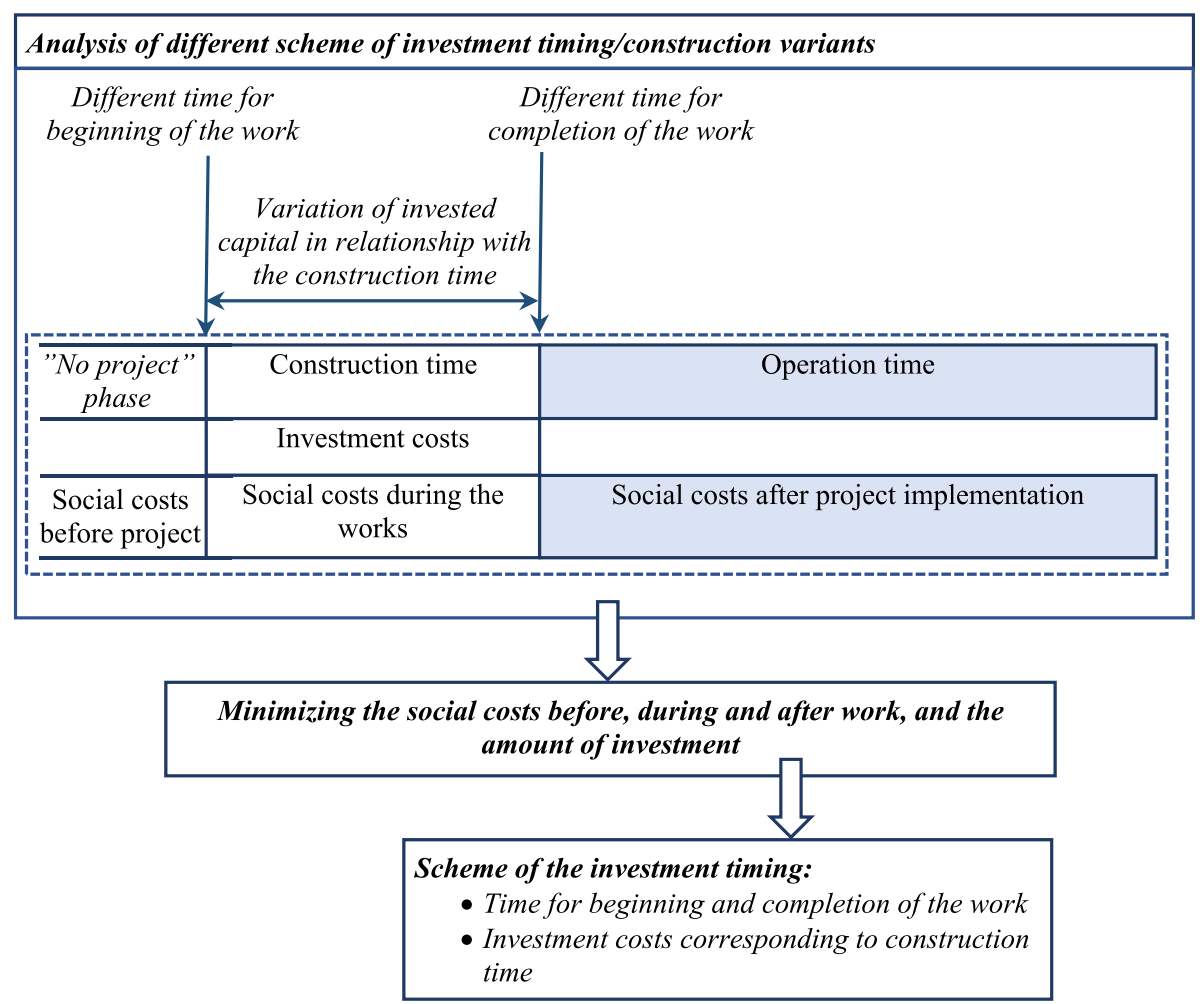

Fig. 8 The structure of the model for selection of the most appropriate investment timing 


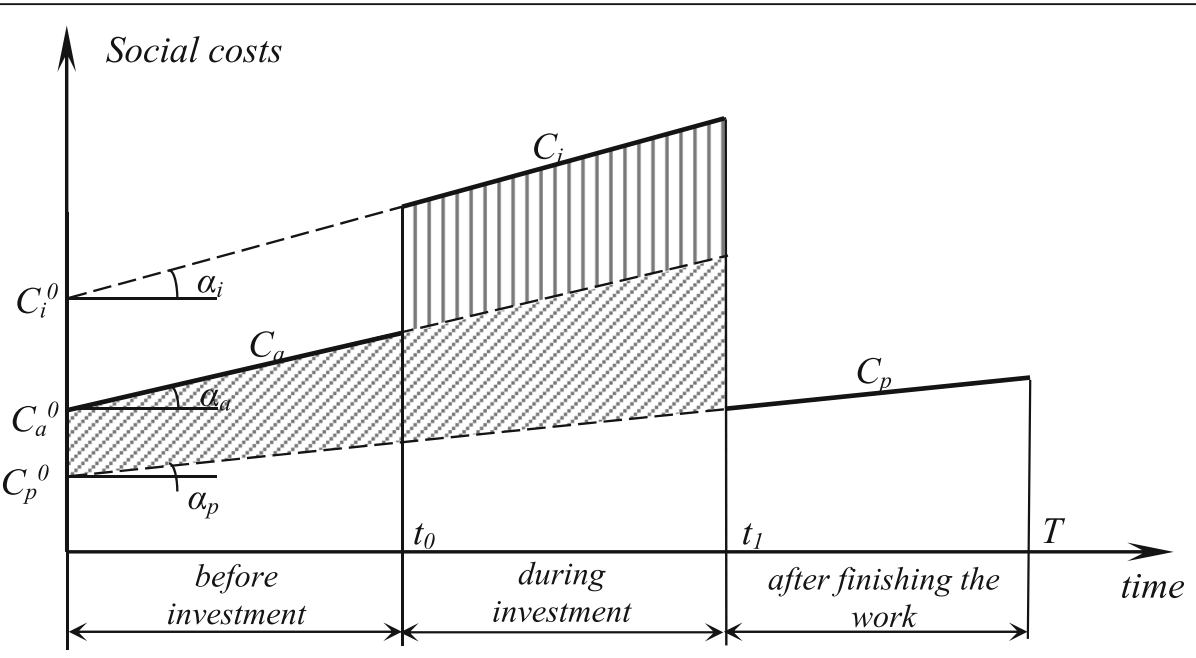

a

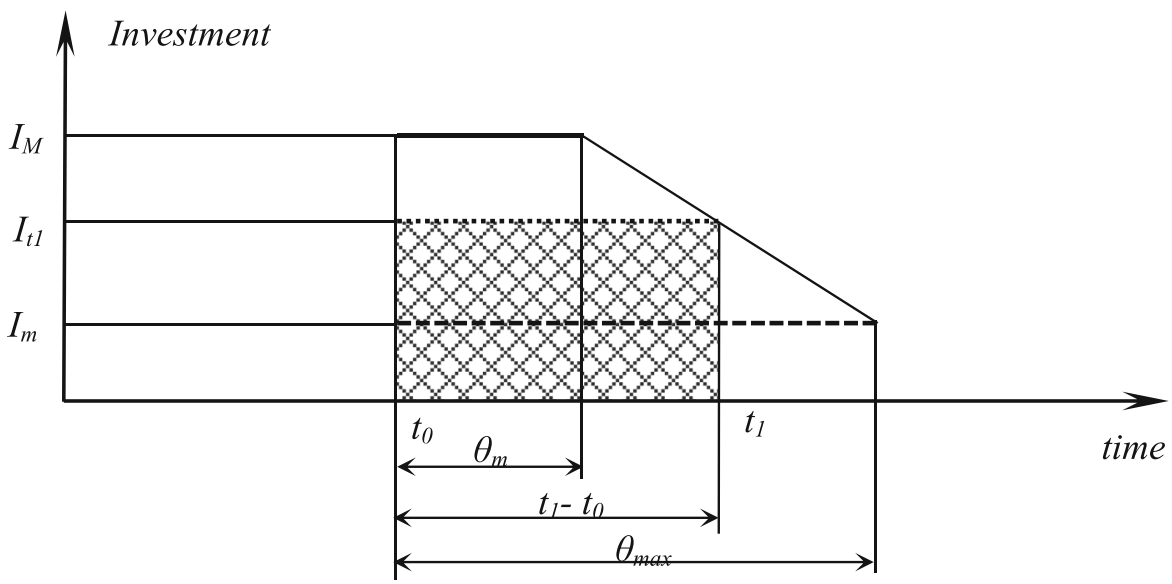

b

Fig. 9 Social costs before, during and after the work in relationship with the amount of investment. (a) Total costs in the "no-project" situation (Ca), during the work (Ci) and after the completion of the work (Cp). (b) The amount of investment, depending on the completion time

$$
\begin{aligned}
L= & C_{a p}^{0} \cdot\left(\frac{1}{1-a}\right) \cdot\left(\frac{1}{a^{t_{1}}}-1\right) \\
& +c_{a p} \cdot\left(\left(1-\frac{1}{a^{t_{1}}}\right) \cdot \frac{a}{(a-1)^{2}}-\frac{t_{1}}{a^{t_{1}}} \cdot\left(\frac{1}{a-1}\right)\right) \\
& +c_{i a} \cdot \frac{1}{a^{t_{0}}} \cdot\left(\frac{1}{a-1}\right) \cdot\left(t_{0}+\left(\frac{a}{a-1}\right)\left(1-\frac{a^{t_{0}}}{a^{t_{1}}}\right)-t_{1} \cdot\left(\frac{a^{t_{0}}}{a^{t_{1}}}\right)\right) \\
& +\left(C_{i a}^{0}+I_{m}+i\left(\theta_{M}+t_{0}-t_{1}\right)\right) \cdot\left(\frac{1}{1-a}\right) \cdot\left(\frac{1}{a^{t_{1}}}-\frac{1}{a^{t_{0}}}\right),
\end{aligned}
$$

which means an explicit function of $t_{0}$ and $t_{1}$.

After some simplifications of the derivative of $\mathrm{L}$ with respect to $t_{1}$, we obtain the following:

$$
\begin{aligned}
& C_{a p}^{0} \cdot \ln a+c_{a p} \cdot\left(\frac{a}{a-1}\right) \cdot \ln a-c_{a p}+c_{a p} \cdot t_{1} \cdot \ln a \\
& \quad+c_{i a} \cdot\left(\frac{a}{a-1} \cdot \ln a-1+t_{1} \cdot \ln a\right) \\
& \quad+i-i \cdot \frac{a^{t_{1}}}{a^{t_{0}}}+\left(C_{i a}^{0}+I_{m}+i \cdot \theta_{M}+i \cdot t_{0}-i \cdot t_{1}\right) \cdot \ln a=0
\end{aligned}
$$

Using the notations for $\gamma_{1}$ and $\gamma_{2}$ (Eq. 17) and denoting:

$$
\gamma_{3}=i \cdot \ln a
$$

then, Eq. (28) can be written as follows: 


$$
\gamma_{1} \cdot t_{1}+\gamma_{2}+\gamma_{3} \cdot t_{0}=i \cdot a^{t_{1}-t_{0}}
$$

The solution of $t_{1}$ in Eq. (30) depends on the unknown $t_{0}$, the starting time of the work. For this reason, we may appeal to the relationship between $t_{1}$ and $t_{0}$ :

$$
\mathrm{t}_{1}{ }^{(s)}-\mathrm{t}_{0}{ }^{(s)}=\theta_{m}+s, \text { with } s=\overline{0 . . S},
$$

where $S=\theta_{M}-\theta_{m}$, that is, the maximum additional time for the completion of the work.

We obtain the pairs of values $\left(t_{1}^{(s)}, t_{0}^{(s)}\right)$, which correspond to the specific amount of loss, L, from Eq. (30). We denote by:

$$
\left\{\begin{array}{l}
\mathrm{y}_{1}{ }^{(s)}=\gamma_{1} \cdot \mathrm{t}_{1}{ }^{(s)}+\gamma_{2}+\gamma_{3} \cdot \mathrm{t}_{0}{ }^{(s)} \\
\mathrm{y}_{2}{ }^{(s)}=i \cdot a^{\mathrm{t}^{1}{ }^{(s)}-\mathrm{t}_{0}(s)}
\end{array}\right.
$$

Considering Eq. (31), Eq. (32) becomes:

$$
\left\{\begin{array}{l}
\mathrm{y}_{1}{ }^{(s)}=\gamma_{1} \cdot \mathrm{t}_{1}{ }^{(s)}+\gamma_{2}+\gamma_{3} \cdot\left(\mathrm{t}_{1}{ }^{(s)}-\theta_{m}-s\right) \\
\mathrm{y}_{2}{ }^{(s)}=i \cdot a^{\theta_{m}+s}
\end{array}\right.
$$

Because $\gamma_{1}+\gamma_{3}=\left(c_{i p}-i\right) \cdot \ln a$, the valid solutions for the pairs $\left(t_{1}^{(s)}, t_{0}^{(s)}\right)$ must respect the following restriction:

$$
\gamma_{2}-\gamma_{3} \cdot\left(\theta_{m}+s\right)<i \cdot a^{\theta_{m}+s},
$$

which is depicted in Fig. 10.

Using the initial notations, Eq. (34) can be written as follows:

$$
\begin{array}{r}
\left(c_{i}-c_{p}\right) c_{i p} \cdot\left(\frac{a}{a-1} \cdot \ln a-1\right) \\
+\left(C_{i}^{0}-C_{p}^{0}+I_{m}\right) \cdot \ln a \\
<i \cdot\left(a^{\theta_{m}+s}+s \cdot \ln a-1\right)
\end{array}
$$

For the completion times $t_{1}^{(s)}$, with $s=\overline{0 . . S}$, and the related solutions of Eq. (31) (see Fig. 10), the starting times of work are the solutions of Eq. (31). Having a set of solution pairs $\left(t_{1}^{(s)}, t_{0}^{(s)}\right)$ for Eq. (30), we can successively assess the loss function, $L$, for each of the time pairs, which means $L(0), L(1), \ldots, L(S)$. The recommended values $\left(t_{1}^{*}, t_{0}^{*}\right)$ respect the following relation:

$$
L^{*}\left(t_{1}^{*}, t_{0}^{*}\right)=\min _{s=\overline{0 . . S}}\left(L\left(t_{1}^{(s)}, t_{0}^{(s)}\right)\right) .
$$

Certainly, the values of time $t_{0}^{*}$ resulting from optimization are relevant to investment decisions only if they are correlated with those imposed by the technical conditions for the start and/or completion of works (e.g. diminution of infrastructure resources, requirements of capacity increase or budget constraints). Therefore, in CBA the time $t_{0}^{*}$ can be introduced as a useful parameter in hierarchizing of several budget projects.

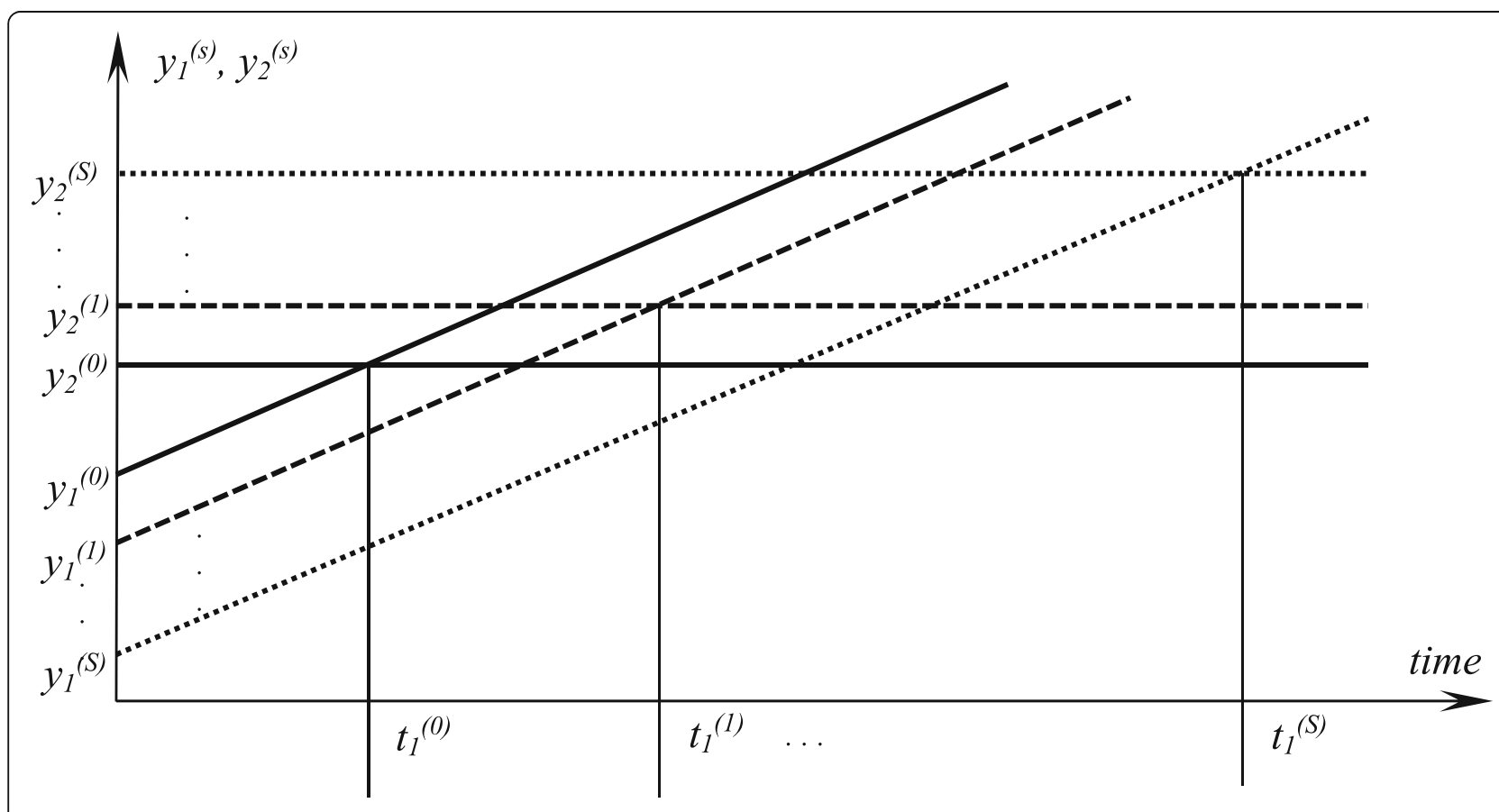

Fig. 10 Solutions for the work completion times 


\section{Results and discussion}

In this section, the presented procedures are exemplified. Firstly, the optimal time of project implementation is determined in two cases of road section upgrading (case A and case B) with work starting at the reference year. Then, another case of a road section upgrading is considered (case C). In this case, the optimal time of project implementation is determined considering that the work can start at time $t_{0}$ (after the reference year).

Table 1 presents the values necessary to determine the optimal time of the completion of the work, $t_{1}^{*}$.

Considering $a=1.05$ (meaning the discounting rate $\Delta$ $=5 \%$ ), the eq. (18) is solved for the cases $\mathrm{A}$ and $\mathrm{B}$ (Fig. 11). In the case A, the optimal construction time is close to the minimum implementation time, meaning that the prolonging of the works is not offset by the reduction of the investment. In the case $B$, the saving of the investment is higher than the social costs implied by the prolonging of the works to 3 years and 10 months.

In the case $C$, the objective is to determine the moments of the starting and the completion of the works for minimum of the losses caused by the social costs before and during the project implementation. Appling the procedure presented in section 5 , the recommendation is the project lasts for 3 years and 6 months, starting 4 years after the reference year.

\section{Conclusions}

Transport infrastructure work requires an extended period of time for completion and, moreover, a large level of investment. During the work, there are impacts on transport operators and users (e.g. speed reduction, additional energy consumption, uncertainty concerning the transport time, congestion, and decreases in traffic safety) and also for the neighbouring population (through increases in, for instance, different pollutants, space fragmentation, and visual discomfort). In the case of road infrastructure, these impacts are also supported by individuals who use their own cars. For all traffic users and for the neighbouring population, work on the transport infrastructure generates even worse impacts by comparison with the "no-project" situation.

The entire set of impacts generated by work on the transport infrastructure must be included in the socio-economic costs for planning studies, in addition to the expected advantages after the completion of the work. The total investment amount in transport infrastructure depends on the necessary implementation time.

In case of high social cost before and/or during the work, the recommended scheme is for achieving the minimum implementation time with maximum investment amount (in order to produce earlier social benefits).

Prolonging the completion time beyond the minimum possible time (from the technical and financial perspectives) could have a positive impact through the reduction in the investment involved (discounted to the reference year). The comparison between the savings in the total investment, due to prolonging the completion time, and the increasing total socio-economic costs, during the work implementation, allows to estimate the optimal time for work.

Table 1 Determining of the optimal time of project implementation

\begin{tabular}{|c|c|c|c|c|}
\hline \multirow[t]{2}{*}{ Element of calculation } & \multirow[t]{2}{*}{ Planning terms/Phase } & \multicolumn{3}{|l|}{ Numerical values } \\
\hline & & Case A & Case B & Case C \\
\hline \multirow{2}{*}{$\begin{array}{l}\text { Annual investment amount } \\
\text { (mill. Monetary units/year) }\end{array}$} & maximum, $I_{M}$ & 660 & 780 & 660 \\
\hline & minimum, $I_{m}$ & 310 & 400 & 300 \\
\hline \multirow{2}{*}{$\begin{array}{l}\text { Implementation time of the project } \\
\text { (years) }\end{array}$} & minimum, $\theta_{m}$ & 3 & 3 & 3 \\
\hline & maximum, $\theta_{M}$ & 5 & 5 & 6 \\
\hline \multirow{3}{*}{$\begin{array}{l}\text { Socio-economic costs due to the } \\
\text { transport infrastructure utilisation, } \\
\text { discounted to the reference year } \\
\text { (mill. Monetary units) }\end{array}$} & before the beginning of work, $C_{a}{ }^{0}$ & 59.5 & 180 & 70 \\
\hline & during the work, $C_{i}^{O}$ & 70 & 225 & 76 \\
\hline & $\begin{array}{l}\text { after the completion of the work and } \\
\text { the beginning of operations in the } \\
\text { new conditions, } C_{p}^{0}\end{array}$ & 50 & 110 & 45 \\
\hline \multirow{3}{*}{$\begin{array}{l}\text { Annual rate of increase in the case } \\
\text { of the socio-economic costs } \\
\text { (mill. Monetary units/year) }\end{array}$} & before the beginning of work, $c_{a}$ & 3.00 & 15.00 & 3.00 \\
\hline & during the work, $c_{i}$ & 6.00 & 23.00 & 5.00 \\
\hline & $\begin{array}{l}\text { after the completion of the work and } \\
\text { the operation in the new conditions, } c_{p}\end{array}$ & 2.10 & 11.00 & 2.00 \\
\hline \multicolumn{2}{|l|}{ Starting time $\left(t_{0}\right)$} & 0 & 0 & 4 years \\
\hline \multicolumn{2}{|l|}{ Completion time $\left(t_{1}^{*}\right)$} & 3 years and 4 months & 3 years and 10 months & 7 years and 6 months \\
\hline
\end{tabular}



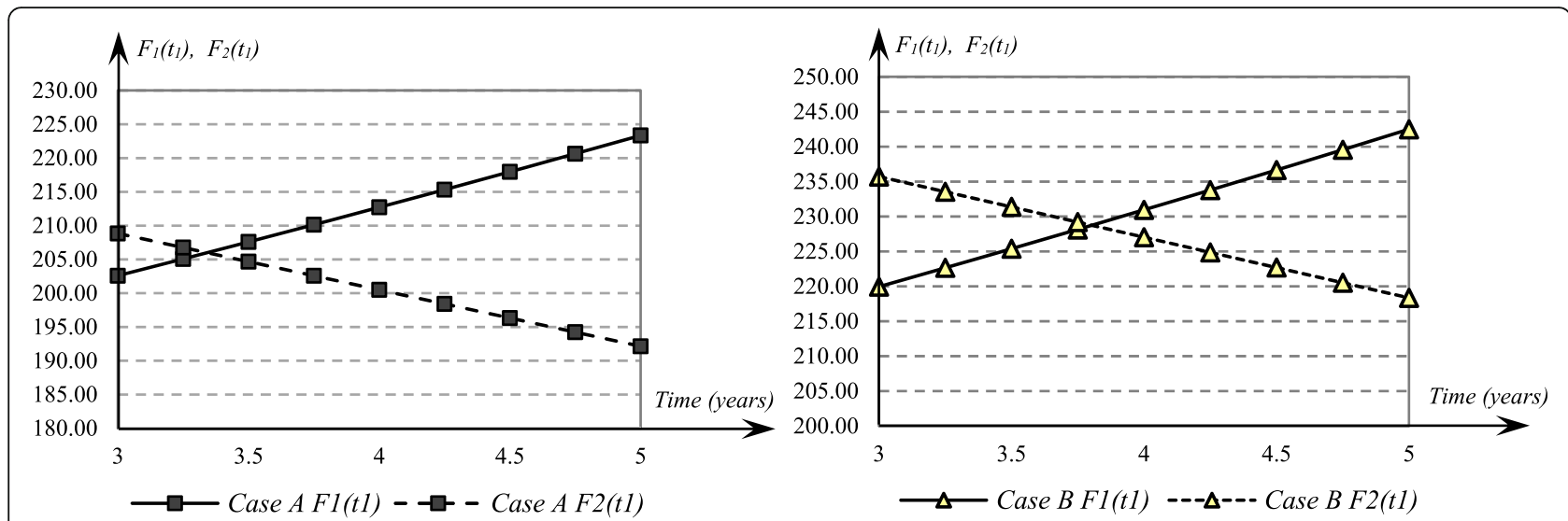

Fig. 11 Graphical solution $\left(\mathrm{F} 1(\mathrm{t} 1)=i a^{t 1} ; \mathrm{F} 2(\mathrm{t} 1)=b_{1}-b_{2} t 1\right)$

Essentially, we attempt to draw the attention of strategic decision makers to the fact that by including the social costs, the planned moments of initiation and completion of a certain project are different from those determined using current methods. The proposed methodology may improve the current assessment methods of the transport projects.

\section{Acknowledgements}

Not applicable.

\section{Funding}

The study is carried out in the framework of the required research activities that the authors must accomplish as professors and researchers of the Department of Transport, Traffic and Logistics from Polytechnic University of Bucharest.

\section{Availability of data and materials}

The datasets used and analysed during the current study are available in the:

- General Transport Master Plan of Romania, Ministry of Transport, Romania, http://www.mt.gov.ro/web14/strategia-in-transporturi/ master-plan-general-transport

- Center for Technical Road Studies - CESTRIN, https://www.cestrin.ro

The datasets generated during the current study are available from the corresponding author.

\section{Authors' contributions}

SR coordinated the study and developed the model of transport infrastructure project evaluation, including procedures that consider social costs during the implementation of the infrastructure projects. DC designed the methodology and solved the models. MP assessed the supplementary cost recorded during construction and road project implementation. MAR used software tools for analysis of numerical model solution and helped to draft the manuscript. All authors read and approved the final manuscript

\section{Competing interests}

The authors declare that they have no competing interests.

\section{Publisher's Note}

Springer Nature remains neutral with regard to jurisdictional claims in published maps and institutional affiliations.
Received: 17 July 2018 Accepted: 16 April 2019

Published online: 08 May 2019

\section{References}

1. Bristow, A., \& Nellthorp, J. (2000). Transport project appraisal in the European Union. Transport Policy, 7(1), 51-60.

2. Veryard, D. (2017). Improving transport cost-benefit analysis: Overview and findings. In Quantifying the socio-economic benefits of transport. Paris: OECD Publishing.

3. European Commission. (2015). Guide to cost-benefit analysis of investment projects. Economic appraisal tool for cohesion policy 2014-2020. Directorate-general for regional and urban policy. REGIO DG 02. Publications Office of the European Union. In Luxembourg.

4. Annema, J. A., Frenken, K., Koopmans, C., \& Kroesen, M. (2017). Relating costbenefit analysis results with transport project decisions in the Netherlands. Letters in Spatial and Resource Sciences, 10(1), 109-127.

5. Mouter, N., Annema, J. A., \& van Wee, B. (2013). Attitudes towards the role of cost-benefit analysis in the decision-making process for spatialinfrastructure projects: A Dutch case study. Transportation Research Part A, $58,1-14$.

6. Sager, T. $\varnothing$. (2016). Why don't cost-benefit results count for more? The case of Norwegian road investment priorities. Urban, Planning and Transport Research, 4(1), 101-121.

7. Damart, S., \& Roy, B. (2009). The uses of cost-benefit analysis in public transportation decision-making in France. Transport Policy, 16, 200-212.

8. Salling, K. B., \& Banister, D. (2009). Assessment of large transport infrastructure projects: The CBA-DK model. Transportation Research Part A, 43, 800-813.

9. Short, J., \& Kopp, A. (2005). Transport infrastructure: Investment and planning. Policy and research aspects. Transport Policy, 12, 360-367.

10. OECD -, E. C. M. T. (2005). National systems of transport infrastructures planning. ECMT round table 128. OECD publication service. In France.

11. Macharis, C., \& Bernardini, A. (2015). Reviewing the use of multi-criteria decision analysis for the evaluation of transport projects: Time for a multiactor approach. Transport Policy, 37, 177-186.

12. Beria, P., Maltese, I., \& Mariotti, I. (2012). Multicriteria versus cost benefit analysis: A comparative perspective in the assessment of sustainable mobility. European Transport Research Review, 4, 137-152.

13. Browne, D., \& Ryan, L. (2011). Comparative analysis of evaluation techniques for transport policies. Environmental Impact Assessment Review, 31, 226-233.

14. Geurs, K. T., Boon, W., \& van Wee, B. (2009). Social impacts of transport: Literature review and the state of the practice of transport appraisal in the Netherlands and the United Kingdom. Transp Rev, 29(1), 69-90.

15. Lami, I.M., Abastante, F., Bottero, M., Masala E. \& Pensa S. (2014). Integrating multicriteria evaluation and data visualization as a problem structuring approach to support territorial transformation projects. EURO Journal on Decision Processes, 2(3-4), 281-312

16. Munda, G. (2006). Social multi-criteria evaluation for urban sustainability policies. Land Use Policy, 23(1), 86-94. 
17. Nijkamp, P., Ubbels, B., \& Verhoef, B. (2002). Transport investment appraisal and the environment. Amsterdam: Tinbergen Institute Discussion Paper. Free University Amsterdam.

18. Jones, H., Moura, F., \& Domingos, T. (2014). Transport infrastructure project evaluation using cost-benefit analysis. Procedia - Social and Behavioral Sciences, 111, 400-409.

19. Fichert, F. (2017) Transport policy planning in Germany - An analysis of political programs and investment masterplans. European Transport Research Review 9(28), 1-12

20. Bonnafous, A., \& Roy, W. (2007). Évaluation, financement et programmation des investissements : chapitre 7. In Maurice J, Crozet Y (Eds). Le calcul économique dans le processus de choix collectif des investissements de transport. Collection Méthodes et Approches. PREDIT. Economica. ISBN-10: 2717854258. ISBN-13: 978-2717854251, 227-248

21. Wee, V. B. (2012). How suitable is CBA for the ex-ante evaluation of transport projects and policies? A discussion from the perspective of ethics. Transport Policy, 19(1), 1-7.

22. Independent Evaluation Group. (2010). Cost-Benefit Analysis in World Bank Projects. Washington, DC: World Bank. License: CC BY 3.0 IGO. https:// openknowledge.worldbank.org/handle/10986/2561

23. Vickerman, R. (2007). Cost-benefit analysis and large-scale infrastructure projects: State of the art and challenges. Environment and Planning Part B, $34,598-610$

24. Naess, P. (2006). Cost-benefit analysis of transportation investments. Neither critical nor realistic. Journal of Critical Realism, 5(1), 32-60.

25. Barfod, M.B., Jensen, A.V. \& Leleur, S. (2011). Examination of Decision Support Systems for Composite CBA and MCDA Assessments of Transport Infrastructure Projects. In Shi Y., Wang S., Kou G., Wallenius J. (Eds). New State of MCDM in the 21st Century. Lecture Notes in Economics and Mathematical Systems, 648. Springer Berlin-Heidelberg, 167-176

26. Joumard, R. \& Nicolas, J-P. (2010). Transport project assessment methodology within the framework of sustainable development. Ecological Indicators 10(2), 136-142.

27. Dodgson, J. S., Spackman, M., Pearman, A., \& Phillips, L. D. (2009). Multicriteria analysis: A manual. London: Department for Communities and Local Government.

28. Cundric, A., Kern, T., \& Rajkovic, V. (2008). A qualitative model for road investment appraisal. Transport Policy, 15, 225-231.

29. Ferreira, L., \& Lake, M. (2002). Towards a methodology to evaluate public transport projects. Physical Infrastructure Centre Research Report 02-03. School of Civil Engineering. Brisbane: Queensland University of Technology.

30. Hayashi, Y., \& Morisugi, H. (2000). International comparison of background concept and methodology of transportation project appraisal. Transport Policy, 7(1), 73-88.

31. Mishr, S., Khasnabis, S., \& Swain, S. (2013). Multi-entity perspective transportation infrastructure investment decision making. Transport Policy, $30,1-12$.

32. Gühnemann, A., Laird, J. J., \& Pearman, A. D. (2012). Combining cost-benefit and multi-criteria analysis to prioritise a national road infrastructure programme. Transport Policy, 23, 15-24.

33. Eliasson, J., \& Lundberg, M. (2012). Do cost-benefit analyses influence transport investment decisions? Experiences from the Swedish transport investment plan 2010-21. Transport Reviews, 32(1), 29-48.

34. Beukers, E., Bertolini, T., \& Brömmelstroet, M. (2012). Why cost-benefit analysis is perceived as a problematic tool for assessment of transport plans: A process perspective. Transportation Research Part A, 46(1), 68-78.

35. Barfod, M. B., Salling, K. B., \& Leleur, S. (2011). Composite decision support by combining cost-benefit and multi-criteria decision analysis. Decision Support Systems, 51, 167-175.

36. European Parliament (2013) Regulation (EU) No 1303/2013 of the European Parliament and of the Council of 17 December 2013, Official Journal of the European Union L347/320.

37. Johansson, E., Winslott Hiselius, L., Koglin, T. \& Wretstrand, A. (2017). Evaluation of public transport: regional policies and planning practices in Sweden, Urban. Planning and Transport Research, 5(1), 59-77

38. Tricker, R. C. (2007). Assessing cumulative environmental effects from major public transport projects. Transport Policy, 14, 293-305.

\section{Submit your manuscript to a SpringerOpen ${ }^{\circ}$ journal and benefit from:}

- Convenient online submission

- Rigorous peer review

- Open access: articles freely available online

- High visibility within the field

- Retaining the copyright to your article

Submit your next manuscript at $\boldsymbol{\nabla}$ springeropen.com 